(2) Open Access Full Text Article

\title{
Assessment of skeletal maturation with permanent mandibular second molar calcification stages among a group of Nepalese orthodontic patients
}

\author{
This article was published in the following Dove Press journal: \\ Clinical, Cosmetic and Investigational Dentistry \\ 30 March 2016 \\ Number of times this article has been viewed
}

Jamal Giri'

Basanta Kumar Shrestha ${ }^{2}$

Rajiv Yadav²

Tika Ram Ghimire ${ }^{2}$

'Department of Orthodontics, BP Koirala Institute of Health Sciences, Dharan, ${ }^{2}$ Department of Dentistry, Institute of Medicine, Kathmandu, Nepal
Correspondence: Jamal Giri

Department of Orthodontics, BP Koirala Institute of Health Sciences, Dharan,

Nepal

Tel +9779842060883

Email Nepalipilot@gmail.com
Background: Assessment of growth status of a patient is a key component in orthodontic diagnosis and treatment planning for growing patients with skeletal discrepancy. Skeletal maturation based on hand-wrist radiograph and cervical vertebral maturation (CVM) are commonly used methods of growth assessment. Studies have shown that stages of dental calcification can also be used to assess skeletal maturation status of an individual, whereas other studies have suggested that the relationship between dental calcification and skeletal maturation should be interpreted with caution owing to racial variation.

Objective: To evaluate the relationship between permanent mandibular second molar calcification stages and skeletal maturity assessed by CVM among a group of Nepalese orthodontic patients.

Materials and methods: One hundred and sixty-eight digital radiographs (84 orthopantomograms and 84 lateral cephalograms) were obtained from the records of 84 patients who sought orthodontic treatment in Orthodontic and Dentofacial Orthopaedic Unit, Department of Dentistry, Institute of Medicine, Kathmandu. Two parameters were used in this study, namely, CVM stages from lateral cephalogram and Demirjian index (DI) stages from orthopantomogram. The evaluation of digital radiographs was carried out on a computer screen with a resolution of $1,280 \times 800$ pixels. The association between DI stages of permanent mandibular second molar and CVM stages was assessed.

Results: A statistically significant association was found between DI and CVM stages for both male and female subjects with Pearson's contingency coefficient value of 0.751 and 0.766 for male and female subjects, respectively.

Conclusion: Skeletal maturation can be reliably assessed with dental calcification stages of permanent mandibular second molar for Nepalese orthodontic patients.

Keywords: cervical vertebral maturation, Demirjian index, lateral cephalogram, orthopantomogram

\section{Introduction}

Assessment of growth status of a patient is of paramount importance in the practice of clinical orthodontics. Knowledge of the growth status is a key component in diagnosis and treatment planning, especially in patients with skeletal discrepancy where an orthodontist intends to utilize the growth potential of the patients. ${ }^{1}$ Hence, it is important to know whether the pubertal growth spurt of the patient has been reached.

Several methods have been used to assess the timing of peak pubertal growth spurt, such as chronological age, height and weight measurements, secondary sexual 
characteristics, skeletal maturity evaluation, and dental maturity assessment. Chronological age is not always reliable., ${ }^{2,3}$ Similarly, somatic characteristics such as height and weight changes and secondary sexual characteristics have limited value for immediate clinical judgment. ${ }^{4}$ Although hand-wrist radiograph is a gold standard for skeletal maturity assessment, its use in orthodontic patients increases the radiation exposure to the patients, and it is especially true for young children who need growth assessment the most. It has been found that cervical vertebral maturation (CVM) can be used with the same confidence as hand-wrist radiographs to evaluate skeletal maturity, thus avoiding the need for an additional radiograph. ${ }^{5}$ Hence, skeletal maturation based on CVM on lateral cephalogram has become popular among orthodontists.

Lately, different studies have shown that stages of dental calcification seen in orthopantomogram can be used to assess skeletal maturational status of an individual, ${ }^{1,6-10}$ whereas studies have also suggested that the relationship between dental calcification and skeletal maturation should be interpreted with caution owing to racial variation. ${ }^{1,6,11,12}$

If a strong relationship exists between CVM and dental calcification stages, the stages of dental calcification could be used alongside CVM to assess maturational status of orthodontic patients. Thereby, an additional radiograph for orthodontic patients (hand-wrist radiograph) could be avoided, thus reducing the patient's radiation exposure. Hence, it was hypothesized that there exists a strong association between permanent mandibular second molar calcification stages and CVM stages among Nepalese orthodontic patients. The primary objective of this study was to evaluate the relationship between permanent mandibular second molar calcification stages and skeletal maturity assessed by CVM among a group of Nepalese orthodontic patients. The secondary objective was to correlate the stages of CVM with the stages of permanent mandibular second molar calcification.

\section{Materials and methods}

One hundred and sixty-eight digital radiographs (84 orthopantomograms and 84 lateral cephalograms) were obtained from the records of 84 patients who sought orthodontic treatment in Orthodontics and Dentofacial Orthopaedic Unit, Department of Dentistry, Institute of Medicine Kathmandu, Nepal. All the radiographs were taken following the standard protocols.

Radiographs of Nepalese orthodontic patients of chronological age ranging from 8 to 18 years were enrolled in the study. The patients with the following characteristics were excluded from the study:

1. Abnormal dental conditions such as impaction, transposition, and congenitally missing teeth;
2. history of trauma to the face and neck region;

3. history of previous orthodontic treatment; and

4. poor quality radiograph with image distortion.

Ethical clearance was obtained from the Institutional Review Board of Institute of Medicine for conducting the study. Patient consent was deemed not relevant because the radiographs were obtained from the archives of the department.

Two parameters were used in this study, namely, CVM stages $^{13}$ for skeletal maturity and Demirjian index (DI $)^{14}$ for dental maturity. For each sample, CVM was evaluated by classifying the second (C2), third (C3), and fourth (C4) cervical vertebrae into six stages depending on maturation patterns depicted on the lateral cephalogram using the classification system of Baccetti et al. ${ }^{13}$ For dental maturity evaluation, calcification stages of permanent mandibular left second molars were assessed by one of the eight stages of calcification $(\mathrm{A}-\mathrm{H})$ as per the index described by Demirjian et al. ${ }^{14}$ The evaluation of digital radiographs (orthopantomograms and lateral cephalograms) was carried out on a computer screen with a resolution of $1,280 \times 800$ pixels. After evaluation, each lateral cephalogram was assigned a CVM stage. Similarly, each orthopantomogram was assigned a dental maturity stage.

The following assumptions were made for sample size calculation:

a) Type I error $(\alpha)=0.05$

b) Type II error $(\beta)=0.20$

c) Power $(1-\beta)=0.80$

According to a study conducted among Indian population, ${ }^{4}$ correlation coefficient between dental maturity assessed by $\mathrm{DI}^{14}$ and $\mathrm{CVM}^{13}$ was found to be 0.85 and 0.86 for male and

Table I Distribution of chronological ages of all subjects grouped by CVM stages

\begin{tabular}{lllll}
\hline CVM stage & Sex & $\begin{array}{l}\text { Number of } \\
\text { subjects }\end{array}$ & $\begin{array}{l}\text { Chronological age } \\
\text { (years) }\end{array}$ \\
\cline { 3 - 5 } & & 7 & Average & SD \\
\hline Stage I & Male & 70.42 & 0.78 \\
Stage 2 & Female & 7 & 8.85 & 0.89 \\
& Male & 7 & 12.14 & 1.06 \\
Stage 3 & Female & 7 & 10 & 1.73 \\
& Male & 7 & 13.57 & 0.53 \\
Stage 4 & Female & 7 & $12.7 \mathrm{I}$ & 0.95 \\
& Male & 7 & 14.42 & 0.48 \\
Stage 5 & Female & 7 & 14.42 & $1.5 \mathrm{I}$ \\
& Male & 7 & 15.58 & 1.06 \\
Stage 6 & Female & 7 & 15.42 & $0.8 \mathrm{I}$ \\
& Male & 7 & 17.57 & 0.53 \\
& Female & 7 & 16.42 & $1.5 \mathrm{I}$ \\
\hline
\end{tabular}

Abbreviations: CVM, cervical vertebral maturation; SD, standard deviation. 
Table 2 Association between CVM and DI for female subjects (contingency table)

\begin{tabular}{|c|c|c|c|c|c|c|c|}
\hline \multirow[t]{2}{*}{ CVM stages } & \multicolumn{6}{|l|}{ DI stages } & \multirow[t]{2}{*}{ Total } \\
\hline & & D & $\mathbf{E}$ & $\mathbf{F}$ & $\mathbf{G}$ & $\mathbf{H}$ & \\
\hline \multirow[t]{2}{*}{ Stage I } & Frequency & 4 & 3 & & & & 7 \\
\hline & Percentage & 57.10 & 42.90 & & & & 100 \\
\hline \multirow[t]{2}{*}{ Stage 2} & Frequency & 2 & 4 & 1 & & & 7 \\
\hline & Percentage & 0.286 & 57.10 & 14.30 & & & 100 \\
\hline \multirow[t]{2}{*}{ Stage 3} & Frequency & & 1 & 2 & 3 & 1 & 7 \\
\hline & Percentage & & 14.30 & 28.60 & 42.90 & 14.30 & 100 \\
\hline \multirow[t]{2}{*}{ Stage 4} & Frequency & & & & 5 & 2 & 7 \\
\hline & Percentage & & & & 71.40 & 28.60 & 100 \\
\hline \multirow[t]{2}{*}{ Stage 5} & Frequency & & & & 4 & 3 & 7 \\
\hline & Percentage & & & & 57.10 & 42.90 & 100 \\
\hline \multirow[t]{2}{*}{ Stage 6} & Frequency & & & & & 7 & 7 \\
\hline & Percentage & & & & & 100 & 100 \\
\hline
\end{tabular}

Note: $\chi^{2}(20)=59.738$; Pearson's contingency coefficient $(C)=0.766, P<0.00$ I (significant).

Abbreviations: CVM, cervical vertebral maturation; DI, Demirjian index.

female subjects, respectively. Comparing these values with standard Cohen's correlation table, keeping power of study as 0.80 , seven subjects were needed for each group. There were six groups according to CVM stages (CVM1-CVM6) with each group comprising seven males and seven females with a total of 84 samples.

Data collection was done using Microsoft office Excel sheet. Chi-square values and Pearson's contingency coefficients were calculated using IBM SPSS Statistics version 20 (IBM Corporation, Armonk, NY, USA). Twenty-five percentage of lateral cephalograms and orthopantomograms were reassessed 2 weeks after the initial assessment to calculate the intraobserver reliability.

\section{Results}

The average chronological ages of male and female subjects were 13.99 and 12.97 years, respectively. It was found that

Table 3 Association between CVM and DI for male subjects (contingency table)

\begin{tabular}{llllllll}
\hline CVM stages & DI stages & & & & \multicolumn{2}{c}{ Total } \\
\cline { 2 - 6 } & & D & E & F & G & H & \\
\hline Stage I & Frequency & I & 2 & 4 & & & 7 \\
& Percentage & 14.30 & 28.60 & 57.10 & & & 100 \\
Stage 2 & Frequency & & 3 & 3 & $\mathrm{I}$ & & 7 \\
& Percentage & 42.90 & 42.90 & 14.30 & & 100 \\
Stage 3 & Frequency & & & 6 & $\mathrm{I}$ & 7 \\
& Percentage & & & 85.70 & 14.30 & 100 \\
Stage 4 & Frequency & & & 6 & $\mathrm{I}$ & 7 \\
& Percentage & & & 85.70 & 14.30 & 100 \\
Stage 5 & Frequency & & & & 7 & 7 \\
& Percentage & & & & 100 & 100 \\
Stage 6 & Frequency & & & & 7 & 7 \\
& Percentage & & & & 100 & 100 \\
\hline
\end{tabular}

Note: $\chi^{2}(20)=54.253$; Pearson's contingency coefficient $(C)=0.751, P<0.001$ (significant).

Abbreviations: CVM, cervical vertebral maturation; DI, Demirjian index. the average chronological age of male subjects was greater compared with female subjects in each group except stage 4, which was statistically significant (Table 1).

The kappa statistics for intraobserver agreement were found to be 0.87 and 0.82 for DI and CVM assessments, respectively. There was almost perfect intraobserver agreement for both DI and CVM assessments.

A statistically significant association was found between CVM and DI for female (Table 2) and male subjects (Table 3).

It was found that CVM stages 3 and 4 , which represent peak skeletal growth spurt, corresponded with DI stages $F$ and $\mathrm{G}$ for female subjects and DI stage $\mathrm{G}$ for male subjects (Table 4).

\section{Discussion}

This cross-sectional study was conducted in an effort to elucidate the relationship between mandibular permanent second molar calcification stage and skeletal maturation among a group of Nepalese orthodontic patients. Growing patients aged $8-18$ years were enrolled in the study because orthopedic growth modification is possible only at this age. Also, the male and female samples were separately assessed because studies have shown that dental development is affected by sex..$^{14,15}$

Table 4 Association between CVM stages and DI stages for male and female subjects

\begin{tabular}{lll}
\hline CVM stages & DI stages & \\
\cline { 2 - 3 } & Females & Males \\
\hline Stages I and 2 & D and $\mathrm{E}$ & $\mathrm{E}$ and $\mathrm{F}$ \\
Stages 3 and 4 & $\mathrm{~F}$ and $\mathrm{G}$ & $\mathrm{G}$ \\
Stages 5 and 6 & $\mathrm{G}$ and $\mathrm{H}$ & $\mathrm{H}$ \\
\hline
\end{tabular}

Abbreviations: CVM, cervical vertebral maturation; DI, Demirjian index. 
Many studies have attempted to determine whether there is a relationship between the level of skeletal maturity and the developmental stages of the permanent dentition. Demisch and Wartmann, ${ }^{16}$ Chertkow and Fatti, ${ }^{17}$ Coutinho et al, ${ }^{7}$ Krailassiri et al, ${ }^{1}$ and Engström et a ${ }^{18}$ have reported a high correlation between dental and skeletal ages. However, there are studies that have reported low or insignificant correlations between the level of skeletal and dental maturation. ${ }^{19,20}$ The lack of concordance among the results of these studies may be due to the difference in methods used for assessing skeletal and dental maturity and racial variations present. It has been suggested that racial variations also play a role in the relationship of dental and skeletal maturation. ${ }^{1,6,11,12}$ Hence, there was a need of this study among a group of Nepalese orthodontic patients to know whether mandibular second molar calcification stages could be used to assess the skeletal maturation among Nepalese patients.

Demirjian et al's method was used for dental maturity assessment because this method has been found to the easiest and clearest method with low intraexaminer and interexaminer error. ${ }^{4,21}$ Demirjian et al, in his seminal article, had observed the mineralization of all the permanent teeth on the left side of the mandible except third molar to assess the overall dental maturity. ${ }^{14}$ But only the mineralization stages of second permanent molar were used in this study because they closely correspond to the different stages of pubertal growth spurt. Mineralization stages of incisors cannot be used for the purpose because the root formation of these teeth is completed by the age of 9-10 years. There are some obvious drawbacks associated with the selection of mandibular canine and third molars for estimation of maturity. Apex closure of mandibular canine occurs by the age of 13 years, ${ }^{22}$ wherein growth in most children extends upto the age of 16-17 years. Even though Coutinho et $\mathrm{al}^{7}$ and Chertkow ${ }^{6}$ have advocated the use of mandibular canine calcification stages for assessment of skeletal maturity, this method was not adopted for this study because of the aforementioned reason. Krailassiri et $\mathrm{al}^{1}$ suggested that the interpretation of the relationship between the stage of dental and skeletal development of the canine teeth and the late stages of skeletal maturity was not meaningful because they found that a large number of canines and first premolars had already attained apical closure during the later stages of skeletal maturation. The findings of Krailassiri et $\mathrm{al}^{1}$ have been supported by another study by Uysal et al. ${ }^{11}$ According to Usyal et al, ${ }^{11}$ second molar calcification showed the highest correlation with skeletal maturity. On the other hand, third molars are the most commonly missing teeth in human dentition, which makes it an unreliable parameter for maturity assessment.

In this study, the second molar of the mandibular arch was used for assessment of dental maturity because the roots of mandibular second molars are easily visible in orthopantomogram, whereas the maxillary molar roots overlap with numerous anatomic structures such as the zygomatic arch and the maxillary sinus septum obscuring the roots.

Also, permanent second molar on the left side of the mandible was only assessed in this study because:

1. There is no statistically significant difference between the developments of two sides of the mandible..$^{23-26}$ Hence, either side could be chosen.

2. Demirjian et $\mathrm{al}{ }^{14}$ had performed the study on the left side of mandible, and the same index was being used in this study.

Though some authors ${ }^{27}$ believe that there is $3 \%-10 \%$ enlargement of the image on the left side of the mandible on orthopantomogram, this is not a serious drawback, because the DI is based on shape criteria and relative values but not on absolute lengths.

Twenty-five percent age of samples were reassessed for CVM and dental maturity after 2 weeks of initial assessment. The kappa values for CVM and dental maturity assessment were calculated to be 0.824 and 0.867 , respectively. These values were less than those of the studies by Kumar et $\mathrm{al}^{4}$ and Valizadeh et $\mathrm{al},{ }^{28}$ but still were indicative of almost perfect agreement.

This study indicated a statistically significant association between the dental maturity as assessed by mandibular second molar calcification and skeletal maturity evaluated by CVM. The Pearson's correlation coefficients between the dental maturity and the skeletal maturity were found to be 0.751 and 0.766 for males and females, respectively, suggestive of good-to-excellent correlation. Similar correlations were reported by Uysal et a ${ }^{11}$ and Mittal et al ${ }^{29}$ However, studies by Rozylo-Kalinowska et al, ${ }^{10}$ Valizadeh et $\mathrm{al}^{28}{ }^{28}$ and $\mathrm{Ra}{ }^{30}$ have reported a weaker correlation. However, there are studies that have reported a much stronger correlation between dental maturity and CVM compared with this study. ${ }^{4,8}$

This study suggested that DI stages $\mathrm{E}$ and $\mathrm{F}$ showed the highest percent age distribution at stages 1 and 2 of CVM (prepeak skeletal growth) for males. Similarly, DI stage G corresponded with CVM stages 3 and 4 (peak skeletal growth) and DI stage $\mathrm{H}$ corresponded with CVM stages 5 and 6 (postpeak skeletal growth). In females, though, DI stages D and E corresponded with CVM stages 1 and 2 
(prepeak skeletal growth), DI stages F and G corresponded with CVM stages 3 and 4 (peak skeletal growth), and DI stages $\mathrm{G}$ and $\mathrm{H}$ corresponded with CVM stages 5 and 6 (postpeak skeletal growth). The findings of this study differ from the findings of the study by Kumar et $\mathrm{al}^{4}$ and Cossellu et $\mathrm{al}^{31}$ in a sense that males and females reach the peak skeletal growth spurt at slightly different stages of dental maturity. Males are at peak skeletal growth spurt at DI stage G, whereas the females reach the peak at DI stages F and G. The finding of this study, that the peak skeletal growth spurt coincides with DI stage G (particularly in males), supports the findings of previous studies by Chertkow ${ }^{6}$ and Coutinho et al. ${ }^{7}$

According to this study, the mandibular second molar calcification stage can be reliably used for assessment of skeletal maturation of Nepalese orthodontic patients who need growth modification. However, a few studies ${ }^{32,33}$ have shown that the dental development is affected in some enamel pathologies such as molar incisor hypoplasia and amelogenesis imperfecta. Hence, a similar study in patients with enamel pathologies is recommended to evaluate whether dental calcification stages can be used for the assessment of skeletal maturation in those patients.

\section{Conclusion}

1. Skeletal maturation can be reliably assessed with dental calcification stages of permanent mandibular second molar for Nepalese orthodontic patients.

2. The timing of peak skeletal maturation coincides with dental calcification stages $\mathrm{F}$ and $\mathrm{G}$ for females and stage $\mathrm{G}$ for males.

\section{Disclosure}

This study was conducted as a part of a thesis under the guidance of Professor Dr Shrestha. The authors report no other conflicts of interest in this work.

\section{References}

1. Krailassiri S, Anuwongnukroh N, Dechkunakorn S. Relationships between dental calcification stages and skeletal maturity indicators in Thai individuals. Angle Orthod. 2002;72(2):155-166.

2. Moore RN, Moyer BA, DuBois LM. Skeletal maturation and craniofacial growth. Am J Orthod Dentofacial Orthop. 1990;98(1):33-40.

3. Fishman LS. Chronological versus skeletal age, an evaluation of craniofacial growth. Angle Orthod. 1979;49(3):181-189.

4. Kumar S, Singla A, Sharma R, Virdi MS, Anupam A, Mittal B. Skeletal maturation evaluation using mandibular second molar calcification stages. Angle Orthod. 2012;82(3):501-506.

5. Kamal M, Goyal S. Comparative evaluation of hand wrist radiographs with cervical vertebrae for skeletal maturation in 10-12 years old children. J Indian Soc Pedod Prev Dent. 2006;24(3):127-135.

6. Chertkow S. Tooth mineralization as an indicator of the pubertal growth spurt. Am J Orthod. 1980;77(1):79-91.
7. Coutinho S, Buschang PH, Miranda F. Relationships between mandibular canine calcification stages and skeletal maturity. Am J Orthod Dentofacial Orthop. 1993;104(3):262-268.

8. Basaran G, Ozer T, Hamamci N. Cervical vertebral and dental maturity in Turkish subjects. Am J Orthod Dentofacial Orthop. 2007;131(4):447 e413-447 e420.

9. Chen J, Hu H, Guo J, et al. Correlation between dental maturity and cervical vertebral maturity. Oral Surg Oral Med Oral Pathol Oral Radiol Endod. 2010;110(6):777-783.

10. Rozylo-Kalinowska I, Kolasa-Raczka A, Kalinowski P. Relationship between dental age according to Demirjian and cervical vertebrae maturity in Polish children. Eur J Orthod. 2011;33(1): 75-83.

11. Uysal T, Sari Z, Ramoglu SI, Basciftci FA. Relationships between dental and skeletal maturity in Turkish subjects. Angle Orthod. 2004;74(5):657-664.

12. Mappes MS, Harris EF, Behrents RG. An example of regional variation in the tempos of tooth mineralization and hand-wrist ossification. Am J Orthod Dentofacial Orthop. 1992;101(2):145-151.

13. Baccetti T, Franchi L, James A, McNamara J. The cervical vertebral maturation (CVM) method for the assessment of optimal treatment timing in dentofacial orthopedics. Semin Orthod. 2005;11: 119-129.

14. Demirjian A, Goldstein H, Tanner JM. A new system of dental age assessment. Hum Biol. 1973;45(2):211-227.

15. Chaillet N, Demirjian A. Dental maturity in South France: a comparison between Demirjian's method and polynomial functions. J Forensic Sci. 2004:49(5):1059-1066.

16. Demisch S, Wartmann C. Calcification of mandibular third molar and its relationship to skeletal and chronological age in children. Child Dev. 1956;27:459-473.

17. Chertkow S, Fatti P. The relationship between tooth mineralization and early radiographic evidence of the ulnar sesamoid. Angle Orthod. 1979;49(4):282-288.

18. Engström C, Engström H, Sagne S. Lower third molar development in relation to skeletal maturity and chronological age. Angle Orthod. 1983;53(2):97-106.

19. Lewis A, Garn S. The relationship between tooth formation and other maturation factors. Angle Orthod. 1960;30:70-77.

20. Garn S, Lewis A, Bonne B. Third molar formation and its developmental course. Angle Orthod. 1962;44:270-276.

21. Maber M, Liversidge HM, Hector MP. Accuracy of age estimation of radiographic methods using developing teeth. Forensic Sci Int. 2006;159(supp1 1):S68-S73.

22. Proffit WR, Fields HW, Sarver DM. Contemporary Orthodontics. 5th ed. St. Louis, MO: Elsevier; 2012.

23. Nolla C. The development of the permanent teeth. J Dent Child. 1960;27:254-266.

24. Haavikko K. The formation and the alveolar and clinical eruption of the permanent teeth. An orthopantomographic study. Suom Hammaslaak Toim. 1970;66(3):103-170.

25. Bolanos MV, Manrique MC, Bolanos MJ, Briones MT. Approaches to chronological age assessment based on dental calcification. Forensic Sci Int. 2000;110(2):97-106.

26. Gat H, Sarnat H, Bjorvath K, Dayan D. Dental age evaluation. A new six-developmental-stage method. Clin Prev Dent. 1984;6(2): $18-22$.

27. Sapoka AA, Demirjian A. Dental development of the French Canadian child. J Can Dent Assoc (Tor). 1971;37(3):100-104.

28. Valizadeh S, Eil N, Ehsani S, Bakhshandeh H. Correlation between dental and cervical vertebral maturation in Iranian females. Iran $J$ Radiol. 2012;10(1):1-7.

29. Mittal S, Singla A, Virdi M, Mittal B. Co-relation between determination of skeletal maturation using cervical vertebrae and dental calcification stages. Internet J Forensic Sci. 2009;4(2).

30. Rai B. Relationship of dental and skeletal radiograph: maturity indicator. Internet J Biol Anthropol. 2007;2(1). 
31. Cossellu G, Biagi R, Pisani L, Barbieri V, Farronato G. Relationship between mandibular second molar calcification stages and cervical vertebrae maturity in Italian children and young adults. Eur J Paediatr Dent. 2014;15(4):355-359.

32. Tunc ES, Ulusoy AT, Bayrak S, Cankaya S. Dental development in children with severe molar-incisor hypomineralization in Samsun, Turkey. J Oral Sci. 2013;55(3):203-207.
33. Seow WK. Dental development in amelogenesis imperfecta: a controlled study. Pediatr Dent. 1995;17(1):26-30.

\section{Publish your work in this journal}

Clinical, Cosmetic and Investigational Dentistry is an international, peer-reviewed, open access, online journal focusing on the latest clinical and experimental research in dentistry with specific emphasis on cosmetic interventions. Innovative developments in dental materials, techniques and devices that improve outcomes and patient satisfac- tion and preference will be highlighted. The manuscript management system is completely online and includes a very quick and fair peerreview system, which is all easy to use. Visit http://www.dovepress. com/testimonials.php to read real quotes from published authors.

Submit your manuscript here: http://www.dovepress.com/clinical-cosmetic-and-investigational-dentistry-journal 